UCRL-JC-122762

PREPRINT

CONF-9605165--1

\title{
Time-Resolved Diagnostics for Concrete Target Response
}

\author{
D. W. Baum \\ R. M. Kuklo \\ J. E. Reaugh \\ S. C. Simonson
}

This paper was prepared for submittal to the Forty-sixth Annual Bomb and Warhead Technical Symposium Monterey, CA

May 13-15, 1996

May 1996

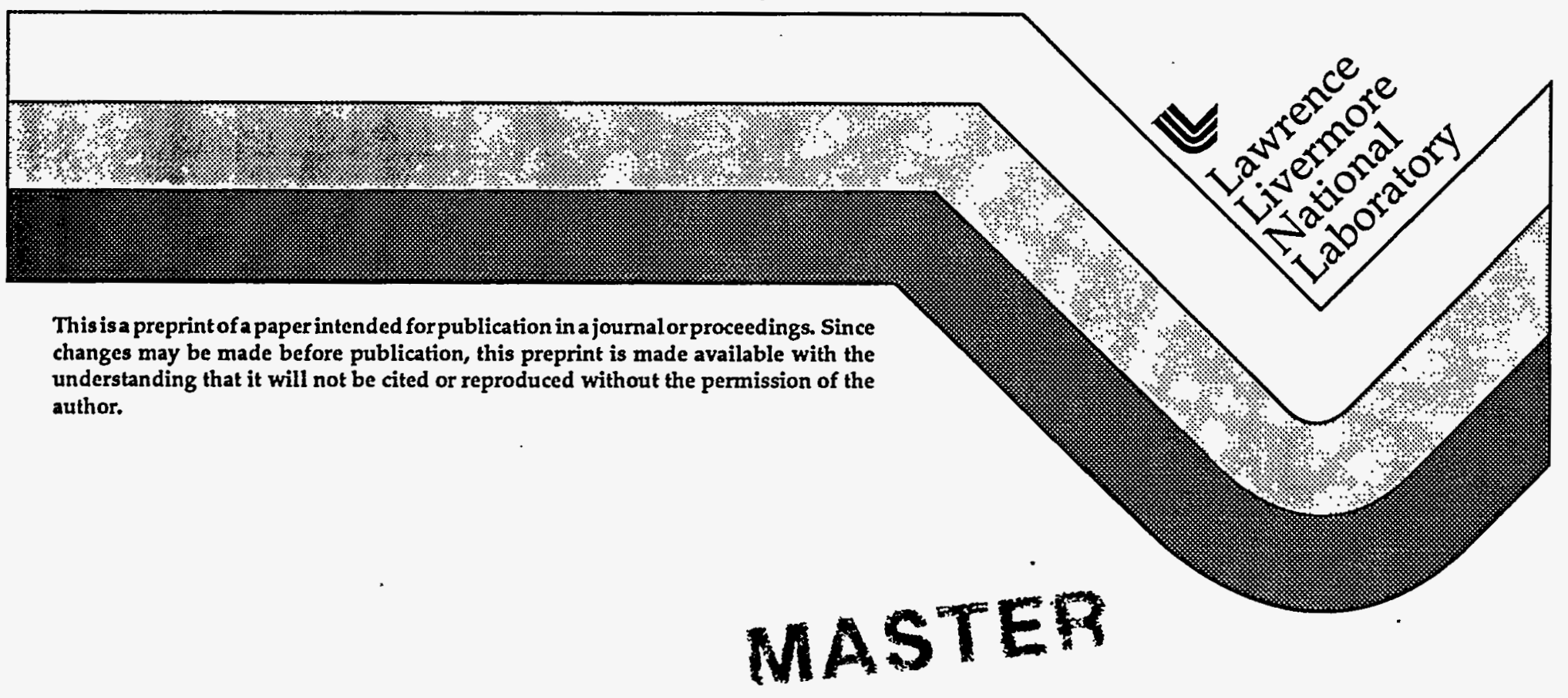




\section{DISCLAIMER}

This document was prepared as an account of work sponsored by an agency of the United States Government. Neither the United States Government nor the University of California nor any of their employees, makes any warranty, express or implied, or assumes any legal liability or responsibility for the accuracy, completeness, or usefulness of any information, apparatus, product, or process disclosed, or represents that its use would not infringe privately owned rights. Reference herein to any specific commercial products, process, or service by trade name, trademark, manufacturer, or otherwise, does not necessarily constitute or imply its endorsement, recommendation, or favoring by the United States Government or the University of California. The views and opinions of authors expressed herein do not necessarily state or reflect those of the United States Government or the University of Califomia, and shall not be used for advertising or product endorsement purposes. 


\title{
46th Annual Bomb and Warhead Technical Symposium May 13-15, 1996 Naval Postgraduate School Monterey, California
}

\section{Time-Resolved Diagnostics for Concrete Target Response}

\author{
Dennis W. Baum, Robert M. Kuklo, John E. Reaugh, and S. Christian Simonson \\ Lawrence Livermore National Laboratory
}

\begin{abstract}
In order to facilitate the design of advanced penetrating weapons for defeating land targets, the interaction of concrete with high-velocity penetrators needs to be better characterized. To aid in this effort, three new types of time-resolved diagnostics are being developed and have been used in two experiments and one demonstration: fiber optic arrays to localize penetrators in space and time, Fabry-Perot velocimetry to record the concrete particle velocity, which is related to the pressure, at specific locations within concrete targets, and micropower impulse radar to provide a non-intrusive measure of the penetrator position-time history in a target.

The two experiments used the fiber optic array and the Fabry-Perot velocimeter to diagnose the response of concrete to penetration by a Viper shaped charge jet. The results were analyzed using the CALE continuum mechanics simulation program, for which a preliminary model of the material properties of concrete was developed. The fiber optic arrays recorded the bow shock at locations 6.4 and $16.9 \mathrm{~cm}$ from the front surfaces. The Fabry-Perot velocimeter measured a free-surface velocity of $0.13 \mathrm{~km} / \mathrm{s}$ at a distance of $3 \mathrm{~cm}$ and obliquity $70^{\circ}$ from the jet, which was moving at an interface velocity of $4.0 \mathrm{~km} / \mathrm{s}$ at a depth of $29 \mathrm{~cm}$. These values imply a pressure of about $6.6 \mathrm{kbar}$ at that location.

The demonstration used micropower impulse radar with a pulse repetition frequency of $0.25 \mathrm{MHz}$ and a cell size of $30 \mathrm{ps}$ to detect and record the motion of a metal penetrator simulant moving inside a cylindrical concrete target.

\section{Intraduction}

Requirements for modern penetrating weapons for use against land targets may include the production of specific effects at given locations within the targets, rather than simply carrying bulk explosives to as great a depth as possible. In order for such special-purpose penetrating weapons to be effective, they need to have survivable case, fuze and payload when delivered against a variety of protected targets. The design of these penetrator weapons and the analysis of their performance requires knowledge not only of penetration mechanics but also of the combined structural response of penetrator, payload and target.
\end{abstract}


For carrying out penetrator weapon design and analysis, the use of twodimensional and three-dimensional continuum mechanics numerical simulations, or "hydrocodes", is vital. For the validation of code calculations with experiments, the experiments must be designed and instrumented to provide time-resolved data, during the penetration process, on fundamental parameters calculated by the code, such as position, velocity, and stress. Of these, stress gauges have been studied and used extensively, but can be noisy and difficult to interpret, particularly for low speed sub-seismic penetration. Accordingly, we have attempted to develop low-noise techniques for timeresolved measurement of position and velocity during penetration. These new diagnostics are the following:

The fiber optic array measures penetrator time-of-arrival and position, as well as a threshold pressure contour.

The Fabry-Perot velocimeter measures the time history of the particle velocity at a well-defined interface in the concrete.

The micropower impulse radar measures the penetrator position-time history in the target and the concrete particle displacement. ciples.

These potentially time-resolved techniques operate according to the following prin-

\section{Principles of Operation}

Fiber optic array.-The fiber optic array measurement technique uses a planar array of 2-mm polymethyl methacrylate (PMMA) fiber optic cables, which may be embedded in the target at multiple locations along the penetrator path. A continuous-wave 15$\mathrm{mW}$ laser diode is used to illuminate one end of the fiber array, and the signal coming through each fiber is detected by a high-sensitivity receiver with a line driver at the other end. The light cutoff caused by a fiber being sheared or crushed is detected by the receiver, and the time is registered on a digital transient recorder. A photograph of the array for Experiment 1 prior to concrete pour is shown in Figure 1.

Fabry-Perot velocimeter.-The Fabry-Perot velocimeter illuminates a surface with a laser beam and records the velocity of that surface by means of changes in an interference pattern [Ref. 1]. The reflected laser light is brought through a Fabry-Perot interferometer and imaged as a pattern of fringes on a detector screen. When the surface moves, its velocity induces a Doppler shift in the reflected light. This causes a shift in the fringe pattern, which is recorded by means of an electronic streak camera. In the current application, a fiber optic probe is used to focus the laser beam on the reflecting surface and collect the reflected light. The velocity along the line of sight is measured directly in absolute terms from the fringe shift.

Micropower impulse radar. - The micropower impulse radar emits a series of wideband radar pulses at a pulse repetition frequency (PRF) on the order of $1 \mathrm{MHz}$. The pulses are reflected off the interface between the conductive penetrator and the dielectric concrete, and the transit time of the pulse to the reflection point and back serves as a range measurement. Subsequent sweeps yield new interface positions. The sample size used here is $30 \mathrm{ps}$, which allows a 1-2 m thick concrete target to be divided into a convenient number of range bins. An identical pulse return pattern will be observed for a reflection point at the same relative position in any of the range bins. For penetrators 


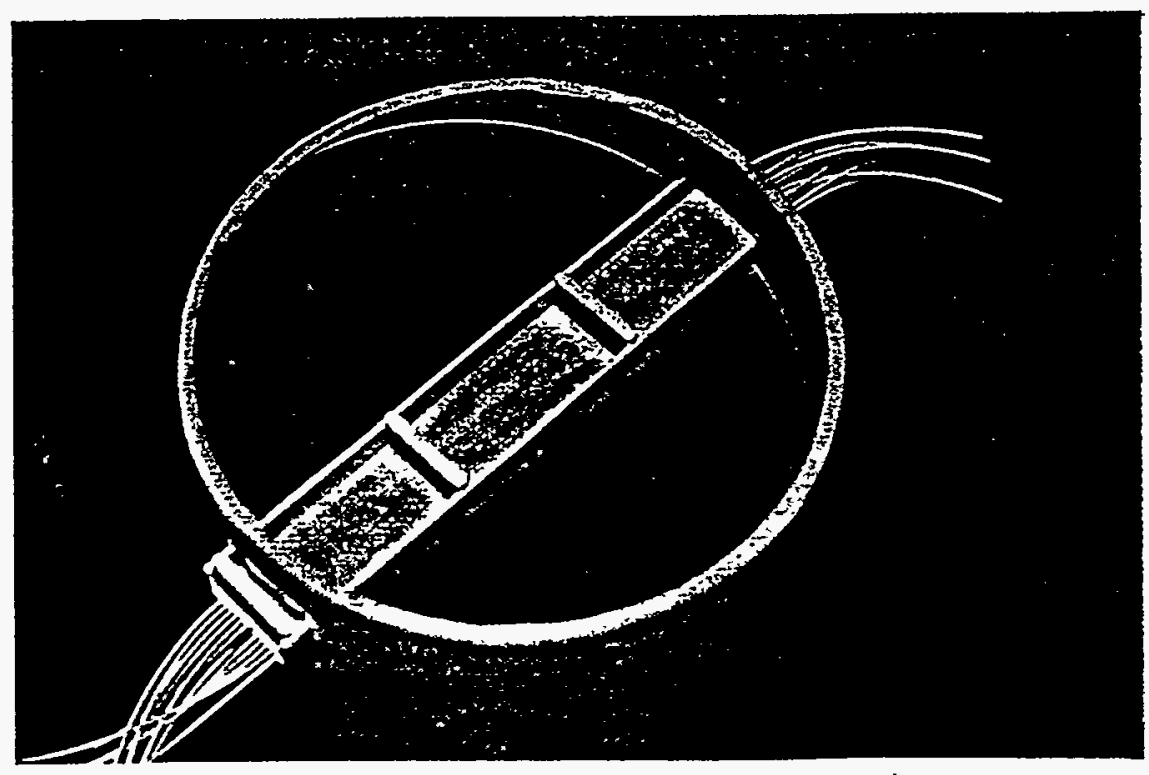

Figure 1.-Photograph of 12-element fiber optic array cemented into holding fixture and positioned in $27-\mathrm{cm}$ diameter cardboard tube prior to filling with concrete.

with speeds up to those of shaped charge jets $(10 \mathrm{~km} / \mathrm{s})$, a PRF on the order of $1 \mathrm{MHz}$ provides enough sample points for accurate tracking of the penetrator through successive range bins.

\section{Experiments using Time-Resolved Diagnostics}

The three techniques described here have been tested in two experiments and one demonstration. The two experiments involved the firing of Viper shaped charges along the centerlines of cylindrical concrete targets. Both of the experiments contained fiber optic arrays, and the second contained a Fabry-Perot velocimeter probe. The demonstration involved the use of the micropower impulse radar in a quasi-static test of a metal rod moving within a concrete cylinder. To aid in planning the experiments and in analyzing the results, calculations were performed using a model of the dynamic material properties of concrete installed in the LLNL continuum mechanics simulation program CALE [Ref. 2].

It should be noted that although the experiments employed a shaped charge, the diagnostic techniques can be applied to slower-moving penetrators, such as explosively formed projectiles (EFP's) and penetrator weapons.

\section{Jet/Concrete Experiments}

In Experiment 1, the 65-mm Viper shaped charge was fired at a standoff distance of $32.5 \mathrm{~cm}$, or 5 charge diameters (CD's). A 12-element fiber optic array was positioned 6.4 $\mathrm{cm}$ from the surface, as shown in Figure 1. In Experiment 2, the Viper shaped charge was fired from a standoff distance of $19.8 \mathrm{~cm}$, or $3 \mathrm{CD}^{\prime} \mathrm{s}$, and a 12-element fiber optic ar- 
ray was placed $16.9 \mathrm{~cm}$ from the front face, using a transverse bore hole in which it was secured with concrete. A Fabry-Perot probe was also inserted in the target, $29.3 \mathrm{~cm}$ from the front face, and surrounded by four piezoelectric crystal pins. A schematic diagram of the Fabry-Perot probe is shown in Figure 2. The laser spot in the Fabry-Perot probe was focused on the center of a $0.25-\mathrm{mm}$-thick copper foil flyer attached to the surface of the concrete. The resulting velocity record is shown in Figure 3. Additional time-of-arrival information for the jet penetration was provided by other buried piezoelectric crystal pins and a foil switch on the front of the target.

\section{Results of Fiber Optic and Fabry-Perot Experiments}

Fiber optic arrays.-The results of the fiber optic experiments are shown in Figure 4 in the form of relative time of signal interruption vs. relative linear position across the array. For Experiment 1, the timing data have uncertainties of as much as $\pm 2 \mu \mathrm{s}$, because the signals were weak, but the times for Experiment 2 have errors of less than $\pm 0.02 \mu \mathrm{s}$. Figure 4 also shows the arrival-time profile of the bow shock and the peak pressures as calculated with CALE. With regard for uncertainties in the experimental data, the timing profiles for the inner fibers agree with the shapes of the calculated bow shocks. The outer fibers, however, tend to lag by several tens of microseconds. We can relate these effects both to the pressure profiles and to the types of damage found in the fiber optic cables.

For the inner fibers, the timing response is related to the pressure distribution in the bow shock. In Experiment 2, the fibers between $-0.48 \mathrm{~cm}$ and $+0.80 \mathrm{~cm}$ follow the calculated pressure arrival times within a standard deviation of $\pm 0.24 \mu \mathrm{s}$. The inferred jet position is $-0.08 \pm 0.08 \mathrm{~cm}$, an offset which is comparable with the jet radius of about $0.10 \mathrm{~cm}$ at this location. Interruption of the fiber optic signal occurred in every case where bow shock pressures exceeded $70 \mathrm{kbar}$ and in some cases at pressures as low as 4 $\mathrm{kbar}$. These inner fibers were heavily damaged, with the ends scorched, the sheaths melted, and up to $1.8 \mathrm{~cm}$ of fiber missing.

For the outer fibers, the timing response is related to the displacement of the fibers. These fibers were sheared but had no missing portions. The interruption times are delayed by $23-33 \mu$ s relative to the arrival of the pressure wave. This late-time breakage occurred at displacements as calculated by CALE that ranged from $0.23-0.25 \mathrm{~cm}$ for fibers at radii of \pm 0.80 to $\pm 1.11 \mathrm{~cm}$ down to $0.15 \mathrm{~cm}$ at larger radii.

Fabry-Perot velocimeter.-The fringe streak record from the Fabry-Perot velocimeter is shown in Figure 3 . The full velocity of $0.13 \mathrm{~km} / \mathrm{s}$ was reached at $5.5 \mu \mathrm{s}$ after jump off. The jet was moving at a velocity of approximately $6.1 \mathrm{~km} / \mathrm{s}$ at this point in the concrete, and the interface velocity was $4.0 \mathrm{~km} / \mathrm{s}$. Hence the elastic wave, with a velocity of about $4.4 \mathrm{~km} / \mathrm{s}$, moved away from the centerline at an angle of about $42^{\circ}$. The piezoelectric crystal pins showed an extended rise time of $0.7 \mu \mathrm{s}$ to $1.7 \mu \mathrm{s}$, which may indicate the ragged nature of the wave front associated with the propagation of shocks in a heterogeneous medium, such as this concrete. 


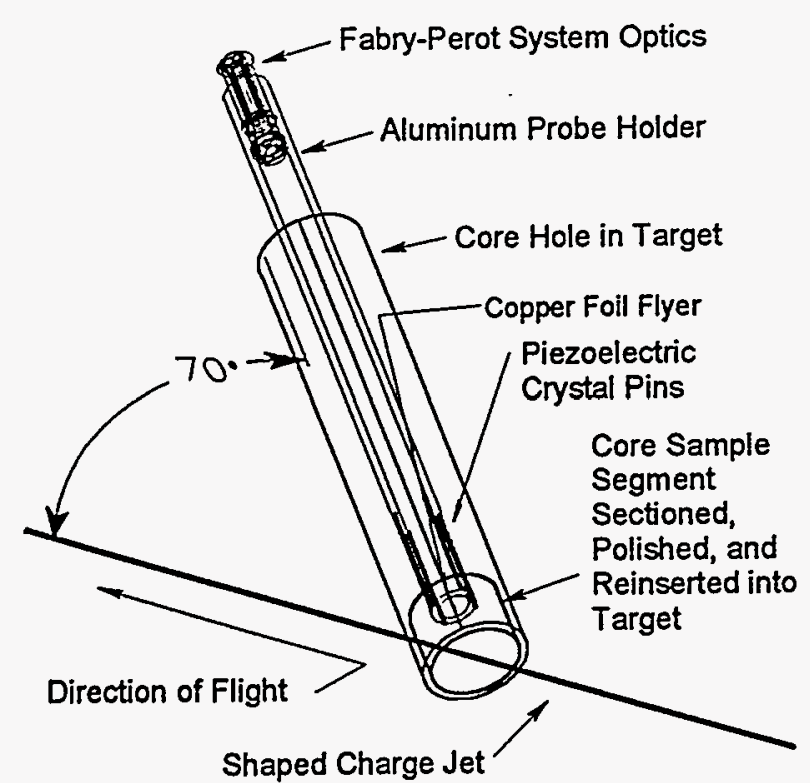

Figure 2.-Schematic diagram of Fabry-Perot probe

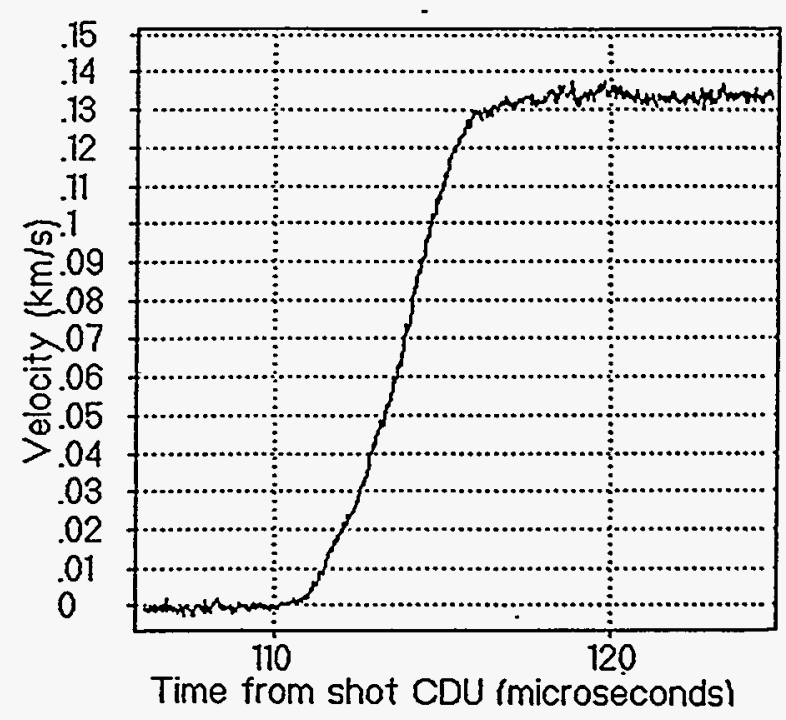

Figure 3.-Experiment 2 Fabry-Perot velocity record.

\section{Concrete Properties Inferred from Velocimetry, Timing and Simulation}

The free-surface velocity from the Fabry-Perot measurement together with timing information on the wave speed allows comparison with hydrocode simulations of jet impact in concrete.

The CALE library model for concrete was used as the basis for our concrete equation of state. That model had been fit to the Hugoniot impact data of Gregson [Ref. 3], which extends to $500 \mathrm{kbar}$. We increased the value of the volume cutoff for pressure so that some expansion from the initial density was possible.

The library model includes a pressure-dependent equivalent strength, which is a customary way of introducing Mohr-Coulomb frictional behavior for rocks and soils. We increased the upper limit of strength to be $10.4 \mathrm{kbar}$, reached at a confining pressure of $10 \mathrm{kbar}$.

For pore compaction, we employed the tensile plasticity and ductile fracture (TEPLA-F) model [Ref. 4] that is in CALE. This has a specific and simple functional form. As a consequence, we do not expect details near the onset of irreversible compaction to be treated accurately with respect to any particular concrete. We do expect, however, that the treatment of an elastic region at low pressure followed by incomplete compaction should show the character of behavior associated with impacts in concrete.

The concrete model in CALE has a characteristic wave speed for the longitudinal elastic precursor of $4.4 \mathrm{~km} / \mathrm{s}$ for pressures in the range of 4 to $20 \mathrm{kbar}$. Grady [Ref. 5] reported a longitudinal elastic wave velocity of $4.45 \mathrm{~km} / \mathrm{s}$ for SAC- 5 concrete similar to that used in Experiment 2. These values are consistent with the timing data in Experiment 2 . 


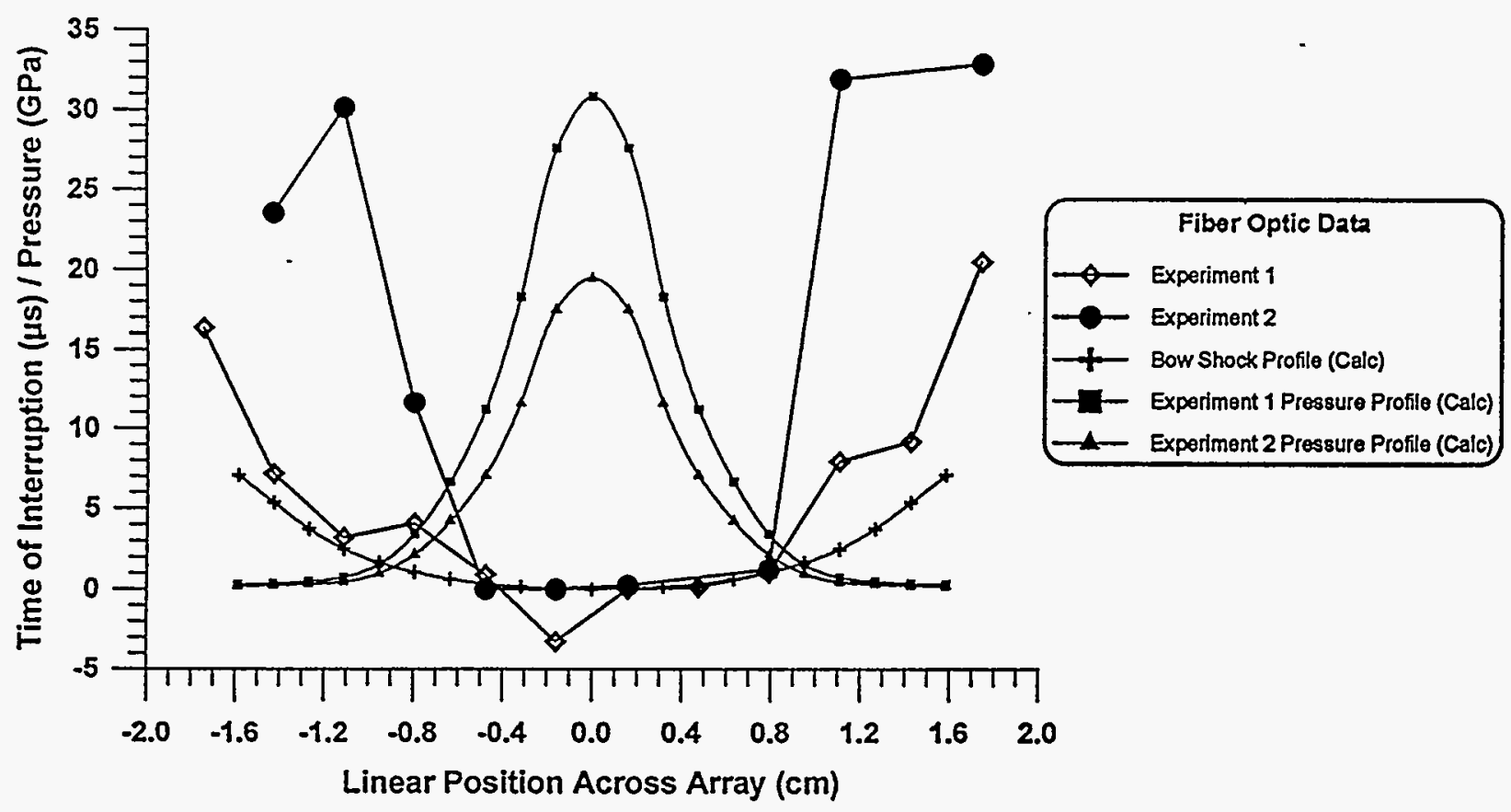

Figure 4.-Time of signal interruption vs. radial position above and below the centerline for 12-channel fiber optic arrays in Experiments 1 and 2, relative to earliest arrival in sheathed fibers. Also shown are the calculated peak pressures at each radius and their arrival times, normalized to arrival at the centerline.

If the foil surface in the Fabry-Perot velocimeter probe had been placed normal to the impinging wave, it would have recorded twice the free-field particle velocity in the concrete. Since the timing data showed that the wave moved at an angle closer to $42^{\circ}$ than the angle of $70^{\circ}$ at which the foil was placed, we can at least set a minimum value for the free-surface velocity. The product of concrete density $\left(2.30 \mathrm{~g} / \mathrm{cm}^{3}\right)$, longitudinal elastic wave speed $(4.4 \mathrm{~km} / \mathrm{s})$ and minimum particle velocity of $0.065 \mathrm{~km} / \mathrm{s}$ from the Fabry-Perot data gives the minimum amplitude of the pressure wave as about $6.6 \mathrm{kbar}$. In a CALE simulation of concrete penetration by a Viper jet, the time required to reach full pressure of $1.6 \mathrm{kbar}$ after the arrival of the elastic wave at the probe location was about $2.2 \mu \mathrm{s}$, while the time taken by the copper flyer to reach its full velocity (at a larger pressure of $6.6 \mathrm{kbar}$ ) was $5.5 \mu \mathrm{s}$.

\section{Micropower Impulse Radar Demonstration}

A demonstration was conducted to test the feasibility of using micropower impulse radar as a concrete penetration diagnostic. The goal was to show single pulse detection of a moving metallic rod inside a concrete target. A $1.9-\mathrm{cm} \times 46-\mathrm{cm}$ aluminum cylinder simulating a penetrator was attached to the end of a dielectric rod and moved manually through a hole drilled down the center of a $27-\mathrm{cm}$ diameter concrete cylinder. For comparison, the penetrator was also moved along the side of the concrete. For this demon- 
stration, the pulse repetition frequency was $0.25 \mathrm{MHz}$, the sample (or cell) size was 30 ps, the number of cells was 4096 , and the sweep time was $16 \mathrm{~ms}$.

The results of the demonstration are shown in Figure 5. The delay time plot shows a clear record of the back and forth motion of the penetrator simulant when it was

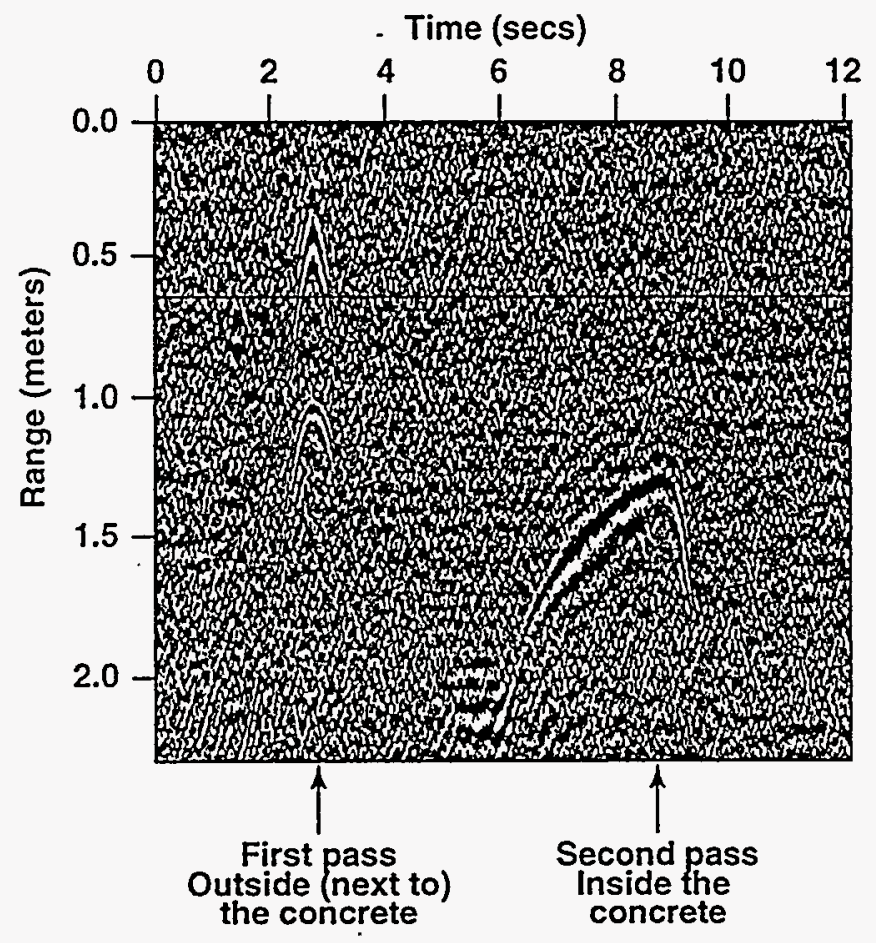

Figure 5.-Range vs. time plot of 4096-channel micropower impulse radar return signal of penetrator simulant alongside of and inside concrete cylinder.

moved along the outside of the concrete and when it was moved inside the concrete. Although the penetrator simulant was moved by hand and thus the situation was clearly quasi-static, even at jet impact speeds the radar measurement may be essentially quasi-static.

\section{Conclusions}

The time-resolved diagnostics reported here are providing useful data on concrete target response. The free-surface velocity from the Fabry-Perot measurement together with timing information on the wave speed have allowed comparison with hydrocode simulations of jet impact in concrete.

Depending on the array spacing, the fiber optic arrays can provide not only the time of arrival of a penetrator but also the profile of the bow shock, along with any offset of the penetrator from the centerline. The present data indicate that the fiber optic array can provide localization of a penetrator within $0.1 \mathrm{~cm}$ in space and $0.25 \mu \mathrm{s}$ in time if the bow shock exceeds $70 \mathrm{kbar}$, so that the fibers are crushed, and will respond with 
somewhat less reliability for bow shocks down to $4 \mathrm{kbar}$. At lower pressure levels, the fibers break when the displacement in the vicinity of the penetrator exceeds $0.25 \mathrm{~cm}$.

Based on the results of the micropower impulse radar demonstration with a $1.9-\mathrm{cm}$ diameter penetrator simulator, the sampling rate could be increased from 0.25 to 1 or even $4 \mathrm{MHz}$, and a 2-m target could be divided into eight range bins to measure velocities up to $10 \mathrm{~km} / \mathrm{s}$. The sensitivity to smaller penetrators has yet to be determined.

\section{Acknowledgments}

The Fabry-Perot velocimetry was set up and the data were reduced by Rex Avara and Richard Whipkey. Instrumentation assistance was provided by John Densberger. The micropower impulse radar demonstration was carried out by Thomas Rosenbury, Carmen Mullenhoff, Jeffrey Mast, and Robert Stever. Lewis Glenn, William Moss, and Kurt Sinz provided helpful comments. This work was supported in part by the Joint DoD/DOE Munitions Technology Development Program. Work performed under the auspices of the U.S. Department of Energy by the Lawrence Livermore National Laboratory under contract No. W-7405-ENG-48.

\section{References}

1. C. F. McMillan, D. R. Goosman, N. L. Parker, L. L. Steinmetz, H. H. Chau, T. Huen, R. K. Whipkey, and S. J. Perry, "Velocimetry of fast surfaces using Fabry-Perot interferometry", Rev. Sci. Instrum. 59, 1-20, 1988.

2. Tipton, R. E. CALE User's Manual, private communication, 1995.

3. V. G. Gregson, Jr., "A Shock Wave Study of Fondu-Fyre WA-1 and a Concrete", General Motors Materials and Structures Laboratory Report MSL-70-30, 1971.

4. J. N. Johnson, F. L. Addessio, "Tensile plasticity and ductile fracture", J. Appl. Phys. 64, 6699-6712, 1988.

5. Dennis E. Grady, "Impact Compression Properties of Concrete", Proceedings of the Sixth International Symposium on Interaction of Nonnuclear Munitions with Structures, Panama City Beach, Florida, pp. 172-175, May 3-7, 1993. 

Technical Information Department - Lawrence Livermore National Laboratory University of California - Livermore, California 94551

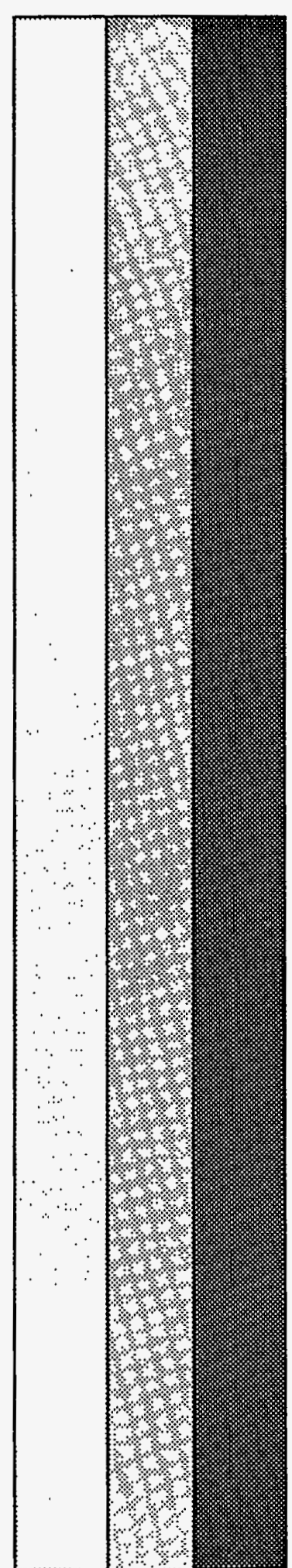

